\title{
FROUDE CRITERION FOR ICE-BLOCK STABILITY
}

\author{
By George D. Ashton \\ (U.S. Army Cold Regions Research and Engineering Laboratory, Hanover, New \\ Hampshire 03755, U.S.A.)
}

\begin{abstract}
The conditions under which a floating fragment of ice is either entrained under the upstream edge of a down-stream ice cover or accumulated up-stream are examined by means of dimensional analysis and a simplified analysis of the moments acting on an idealized ice fragment. The significant parameter descriptive of the critical conditions is found to be a Froude number based on block thickness. The influence of the ratio of thickness to flow depth is shown to be due to the effect of the block constricting the flow cross-section, thus amplifying the velocity in accordance with simple continuity. Under-turning instability occurs at a lower critical velocity than required for vertical submergence. Comparison of experimental data with the theoretical results show good agreement and demonstrates the vital dependence on fragment thickness as well as providing a criterion readily applicable to special flow conditions where a Froude number based on flow depth is illogical.
\end{abstract}

RÉsumé. Critère de Froude pour la stabilité d'un bloc de glace. Les conditions dans lesquelles un fragment flottant de glace est soit entraîné sous la bordure amont d'une banquise située à l'aval d'un courant, soit accumulé à l'amont, sont examinées par les moyens de l'analyse des dimensions et d'une analyse simplifiée des moments agissant sur un fragment idéal de glace. Le paramètre descriptif significatif des conditions critiques est un nombre de Froude basé sur l'épaisseur du bloc. On montre que l'influence du rapport de l'épaisseur à la profondeur de l'écoulement est dûe à l'effet du bloc resserrant la section transversale de l'écoulement et amplifiant donc la vitesse du courant en vertu des simples lois de la continuité. L'instabilité au retournement se produit pour une vitesse critique inférieure à celle nécessaire pour la submersion verticale. La comparaison des données expérimentales avec les résultats théoriques fait apparaître une bonne concordance, montre le rôle essentiel joué par l'épaisseur du fragment et procure un critère facilement applicable à des conditions spéciales d'écoulement lorsqu'un nombre de Froude basé sur la profondeur de l'écoulement est illogique.

Zusammenfassung. Froude-Kriterium fur die Stabilität von Eisblöcken. Die Bedingungen, unter denen ein Stück Treibeis entweder unter den Rand einer stromabwärts gelegenen Eisdecke gedrückt wird oder sich stromaufwärts anlagert, werden mit Hilfe einer Dimensionsanalyse und einer vereinfachten Analyse der an einem idealisierten Eisstück angreifenden Momente untersucht. Als wesentlicher Parameter zur Darstellung der kritischen Bedingungen erweist sich eine aus der Blockdicke hergeleitete Froude-Zahl. Der Einfluss des Verhältnisses zwischen Dicke und Gerinnetiefe beruht auf der Tatsache dass der Block den Querschnitt des Gerinnes verringert, wodurch gemäss einfacher Kontinuität die Geschwindigkeit stromaufwärts erhöht wird. Instabilität, die zum Abkippen führt, tritt bei einer geringeren Geschwindigkeit ein als bei der für vertikales Untertauchen benötigten. Vergleiche zwischen Versuchsdaten und theoretischen Ergebnissen zeigen gute Ubereinstimmung und beweisen die wesentliche Abhängigkeit von der Schollendicke. Ausserdem liefern sie ein Kriterium, das ohne weiteres auf spezielle Fliessbedingungen angewandt werden kann, wenn eine aus der Gerinnetiefe abgeleitete Froude-Zahl unlogisch wäre.

\section{INTRODUCTION}

The prediction of the velocity at which a floating fragment of ice will be swept under the leading edge of a down-stream cover is one of the most basic problems in understanding the mechanics of a broken cover of river ice. The solution of this problem has application in determining the initial conditions and evolution of ice jams, in the design of ice booms and ice retention facilities on rivers, in the design of channels to attain a stable ice cover, and in a number of other topics where the accumulation of floating materials under the influence of a flow velocity is important. In keeping with its intrinsic importance, this problem has attracted the attention of a number of investigators over the past few decades. It is surprising, therefore, that the problem has not been adequately solved. Investigators continue to report data in terms of a Froude number based on water depth while obscuring the rather vital dependence on ice thickness. In this paper, dimensional analysis is applied to the problem. The experimental results of a recent comprehensive laboratory investigation (Uzuner and Kennedy, 1972) are examined in the light of the analysis, and the two are shown to be consistent. Specifically the critical velocity is found to be a simple function involving the Froude number based on block thickness and the ratio of block thickness to flow depth, and to be but little affected by the ratio of thickness to length or the Froude number based on depth. 


\section{SUMMARY OF PREVIOUS WORK}

The work previous to 1968 has been summarized by Bolsenga (I968). Early attempts to establish criteria were expressed in terms of a velocity above which a cover will not progress up-stream. Kivisild (r959) apparently introduced the Froude concept and concluded that the limiting value for up-stream progression was given by $F_{H}=V /(g H)^{\frac{1}{2}}=0.08$ wherein $V$ is the velocity, $H$ is the depth just up-stream of the cover, and $g$ is the acceleration due to gravity. Pariset and Hausser (I96I) presented an analysis using the concept of the "no-spill" condition (which assumes that incipient instability coincides with the top up-stream edge of the block submerging), and, assuming vertical sinking of the fragments, obtained the following criterion

$$
V_{\mathrm{c}}=\left[2 g t\left(\frac{\rho-\rho^{\prime}}{\rho}\right)\right]^{\frac{1}{2}}\left(\mathrm{I}-\frac{t}{H}\right)
$$

wherein $V_{\mathrm{c}}$ is the critical velocity measured up-stream of the block, $t$ is the fragment thickness, and $\rho$ and $\rho^{\prime}$ are the densities of the fluid and the fragment respectively. Perhaps under the influence of Kivisild's previous suggestion of an $F_{H}$ criterion, they chose to present their experimental results in the form

$$
\frac{F_{H}}{\sqrt{2}}=\frac{V_{\mathrm{c}}}{(2 g H)^{\frac{1}{2}}}=K\left[\left(\frac{\rho-\rho^{\prime}}{\rho}\right) \frac{t}{H}\right]^{\frac{1}{2}}\left(\mathrm{I}-\frac{t}{H}\right)
$$

thus reinforcing the previous suggestion of an $F_{H}$ criterion. The coefficient $K$ in Equation (2) was included in cognizance of the fact that most floes submerge by under-turning, generally at a lower velocity than predicted by Equation (2) with $K=$ I.o. Since then numerous papers have presented ice-jam data by giving only the value of the associated $F_{H}$ and mentioning $t$ only in passing, if at all (e.g. Michel, 197 I, in press; Oudshoorn, [197 I]).

Recently Uzuner (unpublished) and Uzuner and Kennedy (1972) analyzed the problem, again assuming a "no-spill" condition but considering under-turning to be the governing mode of instability. Uzuner and Kennedy also presented the results of their laboratory experiments in terms of $F_{H}$ and $t / H$ with the added parameters of $t / L$ and $C_{\mathrm{m}}$, the latter an empirically determined "moment coefficient" which is a function of $t / L$ and $\rho^{\prime} / \rho$. Their experimental results covered a range of $\rho^{\prime} / \rho$ from 0.37 to 0.89 and $t / L$ from 0.096 to 0.773 .

As will be shown below, a dimensional analysis suggests that the most significant parameter is a Froude number based on block thickness rather than flow depth. Further, a simplified moment analysis yields results in good agreement with experimental data and without recourse to an empirical parameter.

\section{Dimensional analysis}

The pertinent variables in the problem are the velocity $V_{\mathrm{c}}$, the block thickness $t$, the block length $L$, the flow depth $H$, the weight per unit volume of the fluid and the block, $\gamma=\rho g$ and $\gamma^{\prime}=\rho^{\prime} g$ respectively, and the density of the fluid $\rho$. The weight per unit volume of the air is taken as zero relative to $\gamma$ and is thus not explicitly included in the analysis. Considering first the case of large depths, physical reasoning leads us to expect that instability occurs when the pressure forces due to the velocity exceed the buoyant forces due to the weight difference between the block and the fluid. Accordingly, a ratio of the two forces is expected to be the most significant parameter. The pressure forces may be taken to be proportional to $\rho V_{\mathrm{c}^{2}}$ multiplied by an area chosen to be the length of the block $L$ times its width $B$. The buoyant force at full submergence is $\left(\gamma-\gamma^{\prime}\right) t L B$. The ratio of the two forces is

$$
\frac{V_{\mathrm{c}^{2}}}{\left(\frac{\gamma-\gamma^{\prime}}{\rho}\right) t}
$$


which may be put into the usual form of a densimetric Froude number by substituting $\gamma=\rho g$ and $\gamma^{\prime}=\rho^{\prime} g$ and taking the square root to yield

$$
F_{t} \equiv \frac{V_{\mathrm{e}}}{\left[g t\left(\mathrm{I}-\frac{\rho^{\prime}}{\rho}\right)\right]^{\frac{1}{2}}} .
$$

This Froude number does not include the block length or the flow depth. To complete the dimensional analysis we expect $F_{t}$ to be a function of parameters incorporating these dimensions in the form

$$
F_{t}=f\left(\frac{t}{H}, \frac{t}{L}\right)
$$

where $f$ denotes functional dependence.

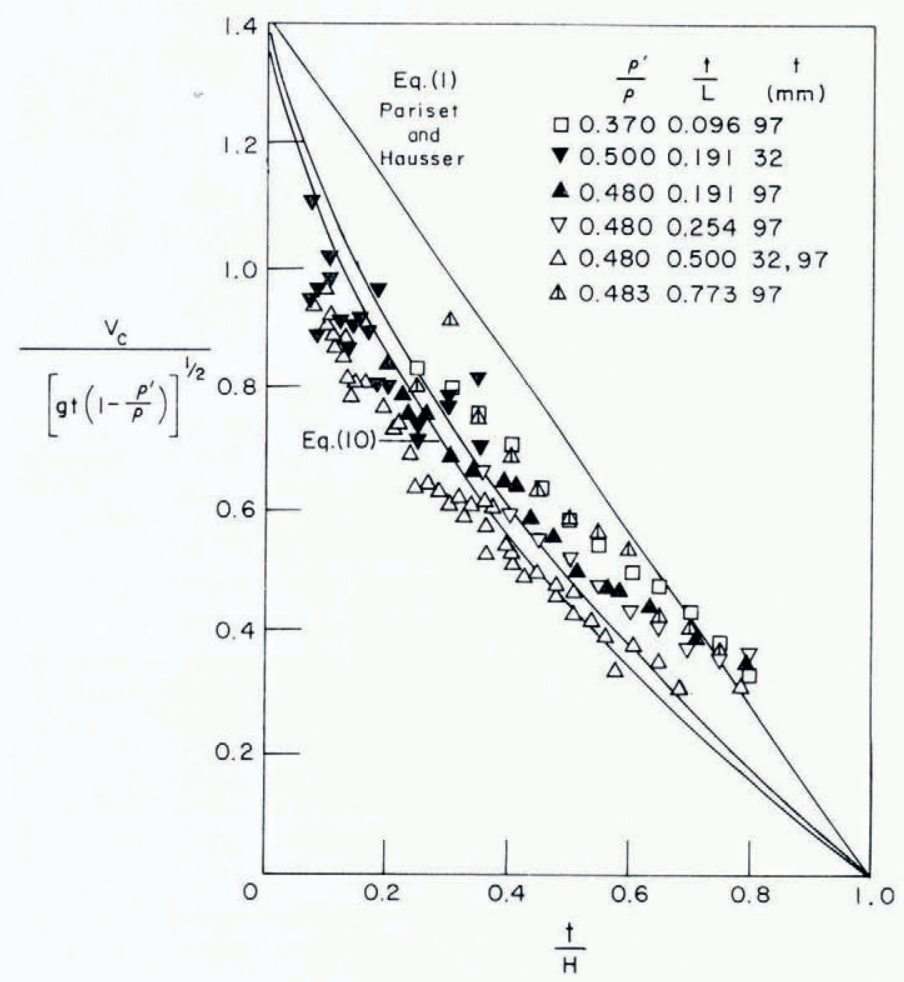

Fig. I. F $F_{t}$ versus $t / H$ (data of Uzuner and Kennedy (1972)).

Examination of Pariset and Hausser's criterion (as given by Equation (I)) suggests that $t / H$ is more important than $t / L$. Accordingly, the data of Uzuner and Kennedy (1972) have been plotted in Figures $\mathrm{I}, 2$ and 3 with $F_{t}$ as the ordinate and $t / H$ as the abscissa, with different symbols assigned to various combinations of $t / L$ and $\rho / \rho^{\prime}$. The choice of coordinates has the additional advantage of allowing ready determination of the critical velocity for conditions when $F_{H}$ is obviously illogical as is the case for special flow configurations or large depths. The data are seen to fall in a narrow band generally below the criterion given by Pariset and Hausser in Equation ( $\mathrm{I}$ ). Before leaving the results of the dimensional analysis it is worth while to point out that the ratio $t / L$ is not entirely irrelevant. Close examination 


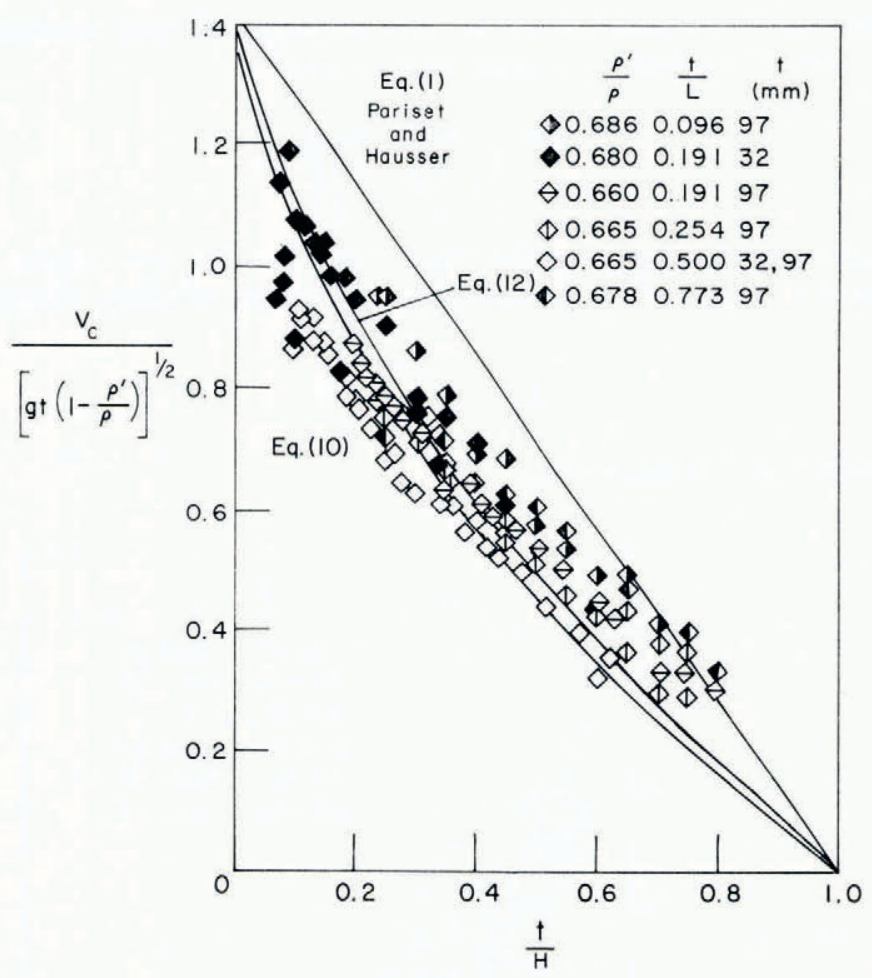

Fig. 2. $F_{t}$ versus $t / H$ (data of Uzuner and Kennedy (1972)).

of the Figures reveals a weak trend of decreasing stability (lower critical velocity) with increasing $t / L$. This trend is particularly evident in Figure 3 where the data for $t / L=0.096$ lies generally above the other data sets. This behavior is not as marked for the same value of $t / L$ at lesser values of $\rho^{\prime} / \rho$; see Figures $\mathrm{I}$ and 2 .

\section{SIMPLIFIED ANALYSIS}

While the analysis presented below is not as detailed as that of Uzuner and Kennedy, it yields simple analytical results which will be shown to be in good agreement with the experimental data. Further, its simplicity enables the physical meaning of the various assumptions used to be explicitly shown, particularly the effect of depth on the critical velocity. It is shown that under-turning occurs at a lower critical velocity than vertical submergence.

A definition sketch is presented in Figure 4. The block is assumed to rotate about its down-stream end and to be submerged such that the bottom is a distance $t_{\mathrm{I}}$ below the water surface. The velocity beneath the block (of unit width) is assumed to be uniform and denoted by $V_{\mathrm{u}}$. Taking moments about point $A$ and assuming equilibrium results in

$$
\frac{\rho^{\prime} g t L^{2}}{2}+\left[\frac{\rho V_{\mathrm{u}^{2}}}{2}-\frac{\rho V_{\mathrm{c}}^{2}}{2}\right] \frac{L^{2}}{2}=\frac{\rho g t_{1} L^{2}}{2}+\frac{\rho g L^{2}}{2} \frac{2 L \sin \alpha}{3} .
$$

The first term in Equation (5) represents the under-turning moment due to the weight of the block, the second term the under-turning moment due to the pressure reduction associated with the Bernoulli effect, the third term the restoring moment due to the weight of the water displaced by that volume of the block described by $t_{1} L$, and the last term the restoring moment 


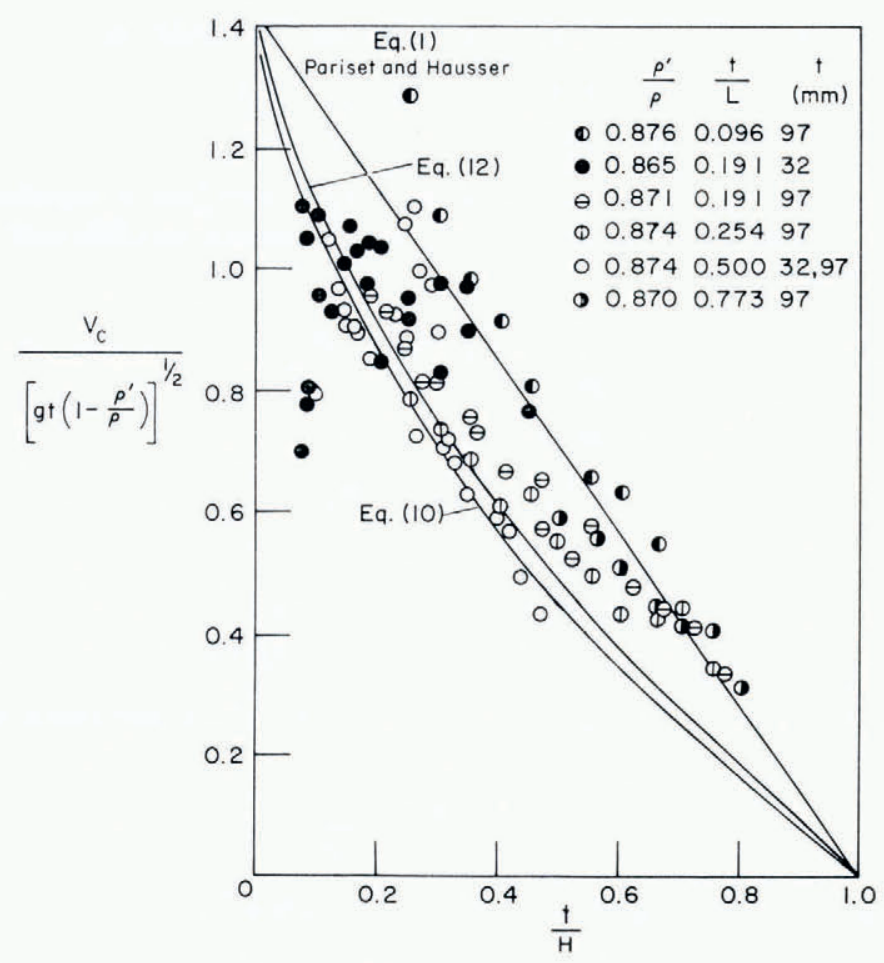

Fig. 3. Ft versus $t / H$ (data of Uzuner and Kennedy (1972)).

due to the weight of the water displaced by that submerged portion of the block triangular in section with height $L \sin \alpha$. It is convenient to divide Equation (5) by $\rho g t L^{2} / 2$ resulting in

$$
\frac{V_{\mathrm{u}^{2}}}{2 g t}-\frac{V_{\mathrm{c}^{2}}}{2 g t}=-\frac{\rho^{\prime}}{\rho}+\frac{t_{\mathrm{I}}}{t}+\frac{2 L \sin \alpha}{3^{t}} .
$$

We now introduce the same no-spill condition used by others. Specifically we assume incipient instability occurs when the top up-stream edge of the block submerges, that is, when

$$
t_{\mathrm{I}}+\frac{V_{\mathrm{u}^{2}}}{2 g}+L \sin \alpha=t \text {. }
$$

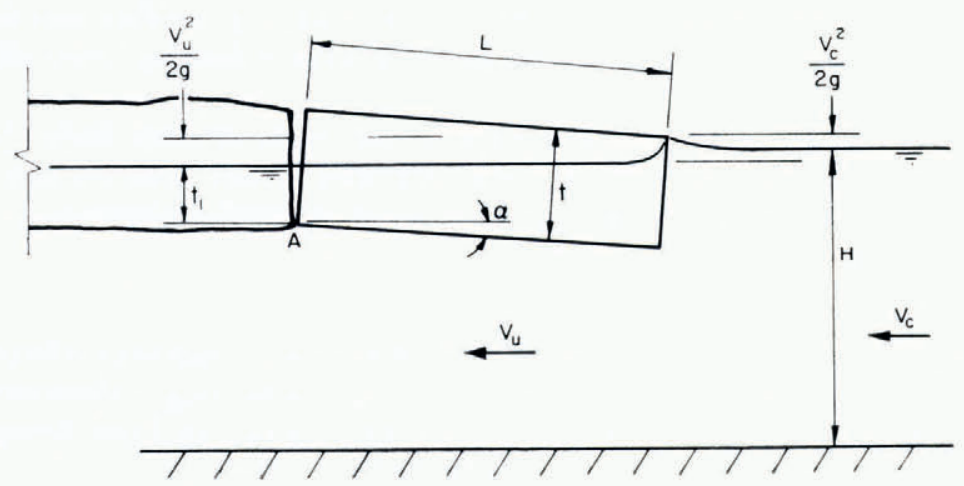

Fig. 4. Definition sketch. 
Substituting for $L \sin \alpha$ in Equation ( 5 a) from Equation (6) results in

$$
\frac{V_{\mathrm{u}^{2}}}{2 g t}-\frac{V_{\mathrm{c}^{2}}}{2 g t}=-\frac{\rho^{\prime}}{\rho}+\frac{2}{3}+\frac{t_{\mathrm{I}}}{3 t}-\frac{V_{\mathrm{u}^{2}}}{3 g t} .
$$

An assumption about $t_{\mathrm{I}}$ must now be introduced and there are a number of reasonable choices. First, it is assumed that $t_{\mathrm{I}}=t \rho^{\prime} \mid \rho$, i.e. the hydrostatic equilibrium depth. For this case Equation (7) leads to

$$
\frac{5 V_{\mathrm{u}^{2}}}{6 g t}-\frac{V_{\mathrm{c}^{2}}}{2 g t}=\frac{2}{3}\left(\mathrm{I}-\frac{\rho^{\prime}}{\rho}\right) .
$$

Introduction of continuity by the relationship

$$
V_{\mathrm{c}}=V_{\mathrm{u}}(\mathrm{I}-t / H)
$$

leads to

$$
\frac{V_{\mathrm{c}}}{\left[g t\left(\mathrm{I}-\rho^{\prime} / \rho\right)\right]^{\frac{1}{2}}}=\frac{2(\mathrm{I}-t / H)}{\left[5-3(\mathrm{I}-t / H)^{2}\right]^{\frac{1}{2}}} .
$$

Alternatively the depth $t_{\mathrm{I}}$ may be taken as the depth at which the block arrives from upstream, which is

$$
t_{\mathrm{I}}=\frac{\rho^{\prime} t}{\rho}-\frac{V_{\mathrm{u}^{2}}}{2 g}+\frac{V_{\mathrm{c}^{2}}}{2 g} .
$$

Again introducing continuity, Equations (7) and (I I) result in

$$
\frac{V_{\mathrm{c}}}{\left[g t\left(\mathrm{I}-\rho^{\prime} / \rho\right)\right]^{\frac{1}{2}}}=\frac{\sqrt{ } 2(\mathrm{I}-t / H)}{\left[3-2(\mathrm{I}-t / H)^{2}\right]^{\frac{1}{2}}} .
$$

Relationships (IO), (I2) and (I) are plotted in Figures I, 2 and 3 . It is clear from an examination of the Figures that Pariset and Hausser's criterion overestimates the critical velocity particularly since Uzuner and Kennedy reported surface velocities about $14 \%$ higher than the mean velocity $V_{\mathrm{c}}$. In view of this uncertainty it is difficult to choose between Equations (IO) and (12) as best representing a stability criterion. The significance of $t / H$ is clearly due to the effect of the block constricting the flow cross-section, thus increasing the velocity in accordance with simple continuity.

The analysis presented above could, of course, be made more detailed by consideration of other effects acting on the block such as the pressure against the up-stream face. It seems more logical, however, to replace the heuristic assumption of the no-spill condition by a formal stability criterion; it is expected that such efforts would lead to an explanation for the observation that blocks of either very small or very large $t / L$ ratio submerge vertically rather than under-turning.

We would have liked to present field data instead of laboratory data. Unfortunately, because of the preoccupation with $F_{H}$, ice thickness and surface velocity have seldom been reported. It is hoped that in the future these will be given proper attention.

\section{Acknowledgements}

The writer gratefully acknowledges helpful discussions with Samuel Colbeck and Wilford Weeks of the U.S. Army Cold Regions Research and Engineering Laboratory. This work was supported by DA Project No. 4A062 103A894, Engineering in Cold Environments.

MS. received ${ }_{15}$ November 1972 and in revised form 24 September 1973 


\section{REFERENCES}

Bolsenga, S. J. 1968. River ice jams - a literature review. U.S. Lake Survey Research Report (Great Lakes Research Center, U.S. Lake Survey, Detroit, Michigan), 5-5, p. 5-169.

Kivisild, H. R. I959. Hanging ice dams. Proceedings of the 8th Congress of the International Association for Hydraulic Research, Vol. 2, paper 23-F, p. I-30.

Michel, B. 1971. Winter regime of rivers and lakes. U.S. Cold Regions Research and Engineering Laboratory. Cold regions science and engineering. Hanover, N.H., Pt. III, Sect. B 1 a, p. 65-71.

Michel, B. In press. Properties and processes of river and lake ice. [Paper presented at International Symposia on the Role of Snow and Ice in Hydrology, Banff, Canada, UNESCO Session 5.]

Oudshoorn, H. M. [1971.] Ice cover formation and associated hydro-dynamic effects in the lower part of the river Rhine. (In [International Association of Hydraulic Research.] I.A.H.R. symposium: ice and its action on hydraulic structures, Reykjavik, Iceland, [8]-10 September 1970. [Delft, International Association of Hydraulic Research], paper 3.0, p. I-19.)

Pariset, E., and Hausser, R. 196r. Formation and evolution of ice covers on rivers. Transactions of the Engineering Institute of Canada, Vol. 5, No. I, p. $4^{\mathrm{I}-49}$.

Uzuner, M. S. Unpublished. Stability of floating ice blocks. [M.S. thesis, University of Iowa, Iowa City, Iowa, 1971.]

Uzuner, M. S., and Kennedy, J. F. 1972. Stability of floating ice blocks. Fournal of the Hydraulics Division, American Society of Civil Engineers, Vol. 98, No. HY 12, p. 2117-33. 